\title{
A República e as práticas científicas
}

\section{The Republic and scientific practices}

\author{
Libânia Xavier \\ Professora do Programa de Pós-graduação em Educação/Universidade Federal do Rio de Janeiro. \\ libaniaxavier@hotmail.com
}

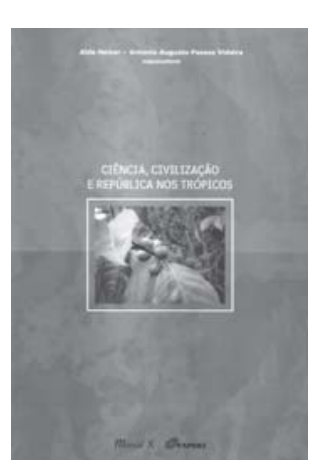

HEIZER, Alda; VIDEIRA, Antonio Augusto Passos (Org.). Ciência,

civilização e República nos trópicos. Rio de Janeiro, Mauad; Faperj, 2010. 384p. iência, civilização e República nos trópicos, que veio a público em
2010, é a segunda coletânea organizada por Alda Heizer e Anto-
nio Augusto Passos Videira. A primeira, intitulada Ciência, civilização
e Império nos trópicos foi publicada em 2001, pela Editora Access (Rio
de Janeiro). Ambas são fruto de colóquios propostos pelos organi-
zadores - o primeiro realizado em 2000 e o segundo, em 2008 - com
o intuito de viabilizar a socialização de estudos afetos à história das
ciências em contextos específicos. Composto por 21 artigos assinados
por diferentes autores, apresenta um variado painel dos saberes e
das práticas científicas em curso na virada do século e nos anos
iniciais da República. Cabe acrescentar que, tal como na primeira
publicação, os artigos apresentam uma complementaridade e orga-
nicidade nem sempre presentes em publicações dessa natureza.
Focalizando sujeitos com inserção em áreas específicas de conhe-
cimento e de intervenção social, os artigos remontam aos grandes
temas que pontuaram o debate intelectual do período. Trata-se, portanto, de relevante contribuição para a história das ciências, campo de pesquisa que se espraia para diálogos sempre profícuos com o pensamento social e a história da cultura, bem como a intelectual e a política. Nesse diálogo que ultrapassa as fronteiras disciplinares, os estudos fertilizam a reflexão sobre os processos de institucionalização e especialização do conhecimento científico, revelando as tensões e negociações, pontos de convergência e de inflexão que nos permitem melhor compreender como se foram delineando os contornos de diferentes campos de saber e os fatores atuantes no desenvolvimento da pesquisa científica em nosso país.

Ao explorar aspectos biográficos dos cientistas de variadas áreas do conhecimento, os autores convergem na percepção de que a busca dos fundamentos da nacionalidade brasileira marcou as trajetórias individuais e coletivas das gerações que participaram dessa empreitada. Essa leitura nos permite perceber, ainda, que tal empreitada correspondeu à premência por superar vários desafios, entre eles a diversidade regional e cultural do país; os limites teóricos que inviabilizavam uma abordagem positiva a respeito da questão racial (frequentemente associada à ideia de degenerescência dos costumes); a necessidade de legitimação das atividades científicas em contraste com as marcas de apatia e ignorância 
do povo (não raro, visto como doente e analfabeto); e, por fim, a desorganização dos setores populares rurais e urbanos (muitas vezes qualificada como uma espécie de 'cegueira política').

A superação da vastidão territorial e a diversidade geográfica e cultural configuram um dos eixos que aglutina o debate intelectual e as práticas científicas em curso no período e, ao mesmo tempo, articula um conjunto de textos do presente livro. Por exemplo, o artigo de Lúcia Lippi Oliveira explora os conceitos de território, região e regionalismo em suas relações com as concepções de nação e com a constituição da geografia como ideologia e campo disciplinar. Nele, a autora faz referência à literatura regionalista dos primeiros anos da República, destacando as representações das partes ou regiões de um Brasil rural e conservador em contraposição a sua outra face, urbana e moderna.

Ao avançarmos na leitura do livro, percebemos que foram essas mesmas representações que animaram o movimento de desbravar o sertão e promover a integração - ainda que desigual - entre o litoral e o interior. O objetivo central era, portanto, estabelecer uma linha de comunicação entre a população rural, os setores populares urbanos e as elites dirigentes. Instaurando uma verdadeira cruzada moral e científica, os intelectuais da Primeira República se embrenharam no interior do país para promover a abertura de estradas e instalar linhas telegráficas, conhecer as características e os limites do território nacional, estudar a flora e a fauna e averiguar a ocorrência de doenças típicas da região - entendendo os seus vetores de disseminação e buscando sua cura - ou, ainda, observar e classificar os tipos populacionais quanto a aspectos físico-biológicos, saúde, instrução e dimensões socioculturais.

A esse respeito, o estudo de Simone Kropf sobre o papel de Carlos Chagas no combate às chamadas enfermidades tropicais, assim como o de Alda Heizer a respeito do botânico João Geraldo Kuhlmann oferecem análises instigantes a respeito das missões desses cientistas e de seu lugar na história e na historiografia das ciências no Brasil. Como se pode comprovar com a leitura desses e de outros artigos, tanto as expedições que adentravam o interior do território nacional quanto as reformas urbanas que modernizaram grandes centros como Rio de Janeiro e São Paulo atestam a urgência de integração territorial (e cultural), assim como o desejo de civilizar o país, apostando no poder da ciência como promotora das mudanças requeridas em diferentes setores da vida nacional.

Deslocando o olhar para o cenário urbano, o artigo de Stella Bresciani aborda os planos de reforma urbana em São Paulo, entre 1890 e 1930, e destaca a contenda entre as concepções de caráter culturalista e as concepções modernas do urbanismo. As primeiras eram orientadas pela ideia de cidade como obra de arte e por medidas de contenção do processo de expansão urbana, de modo a promover uma transição controlada entre campo e cidade. Por seu turno, as concepções mais próximas de uma dimensão científica se opunham a qualquer tipo de nostalgia do passado e propunham soluções técnicas para ajustar as cidades às exigências da vida moderna.

Ainda no cenário urbano, o artigo de Marco A. Pamplona nos permite observar em que medida o desafio de superar o que era visto como desorganização dos setores populares, associado à distância cultural que dificultava a comunicação entre as elites políticas e intelectuais e os setores populares, se materializou, em 1904, na cidade do Rio de Janeiro, na explosão popular que ficou conhecida como Revolta da Vacina. Como demonstra o 
autor, esse movimento - que fugiu ao controle das autoridades e dos homens de ciência -, mais do que uma demonstração de ignorância acerca dos meios modernos de prevenção de doenças, indica um importante ponto de afastamento entre as políticas profiláticas e modernizadoras em curso e os valores e costumes da população da capital do país.

No que tange aos desafios teóricos colocados pela questão racial, Nísia Trindade Lima e Regina Abreu sinalizam a viragem promovida no fazer antropológico com a configuração de uma antropologia cultural, em um contexto ainda marcado por concepções fundadas nos determinismos biológicos e geográficos. Os artigos de Lima, Kropf e Edler tocam outra interessante questão do intrincado contexto intelectual do período, demonstrando até que ponto a luta concorrencial que presidiu o desenvolvimento das práticas e das ideias científicas em nosso país interferiu na consagração ou no esquecimento de algumas teses e de seus autores. Em meio aos diferentes móveis de disputa analisados, podemos destacar as contendas em torno dos diagnósticos sobre a saúde dos brasileiros e suas repercussões sobre a imagem que se queria difundir do país. Vale citar, também, os debates em torno das diferentes concepções sobre o conceito de raça e seus efeitos nas representações sobre a identidade nacional. Não seria demais lembrar que as polêmicas em torno do conceito de raça se fazem presentes, ainda hoje, na formulação e avaliação de políticas de inclusão educacional, desencadeando debates acalorados, como no caso do estabelecimento de cotas para garantir o ingresso de estudantes negros no ensino superior.

Após destacar a atualidade de algumas questões abordadas no livro, ressalto outra viagem que a leitura de determinados artigos podem nos proporcionar. Ela também pode nos conduzir ao que, inspirados nos escritos de Mariza Corrêa, chamaremos de pré-história de certas áreas de conhecimento, tais como medicina, engenharia, antropologia, geografia, psicologia e história. Nessa linha, são analisados os processos de constituição e consolidação, bem como as tensões e inflexões ocorridas na institucionalização de algumas disciplinas específicas.

Em particular, o artigo de Magali Romero Sá articula o desenvolvimento do estudo das doenças características das regiões tropicais ao processo de expansão dos impérios coloniais, nos séculos XVIII e XIX, bem como à proliferação das coleções científicas realizadas por naturalistas e médicos em expedições científicas e divulgadas nos museus e instituições de pesquisa. Por sua vez, Flavio Edler analisa os embates que acompanharam a criação da disciplina de medicina tropical nas faculdades de medicina, destacando que o referido debate foi pontuado pela rejeição ao fatalismo mesológico associado à medicina do Império e pela luta nacionalista em torno a diagnósticos considerados desejáveis sobre a saúde pública brasileira.

No que tange ao desafio de promover a legitimação das teorias e das práticas científicas em um país como o Brasil, o livro apresenta uma multiplicidade de iniciativas. Não por acaso, as análises acabam por levantar diferentes sujeitos - médicos, sanitaristas, botânicos, químicos, biologistas, naturalistas, mineralogistas, engenheiros, urbanistas, antropólogos, literatos, e a lista pode se alongar -, identificando suas redes institucionais e sociais, bem como suas ligações nacionais e internacionais. Desse modo, nos levam a identificar, na diversidade dos sujeitos e de seus fazeres científicos, suas âncoras de reconhecimento social, seja pelo impacto provocado por suas ideias e realizações, seja pelo fato de esses efeitos 
serem, muitas vezes, potencializados pelos postos ocupados em instituições consagradas no meio intelectual. A essa altura, nos deparamos com uma instigante preocupação que marca o conjunto de estudos em tela. Trata-se do interesse por desvendar a trajetória de instituições que, no passado, tiveram extrema importância para o desenvolvimento científico nacional. Hoje, já consolidadas e reconhecidas, tais instituições se tornaram lócus da produção de estudos sobre sua própria história, focalizando (e, ao mesmo tempo, legitimando) seu papel na vida intelectual do país. Por essa via, ficamos conhecendo um pouco mais da história do Instituto Oswaldo Cruz, do Museu Nacional, do Jardim Botânico do Rio de Janeiro, do Observatório Nacional, do Museu Paraense Emílio Goeldi, entre ouras instituições.

Seguindo essa trilha, determinados artigos jogam luz sobre as tensões que permearam as relações entre instituições científicas, intelectuais e Estado. É o caso da análise desenvolvida por Antonio Augusto Videira a partir de um relatório encomendado pelo ministro da Agricultura ao diretor do Observatório Nacional, Henrique Morize. Conforme demonstrou Videira, o autor do relatório se utilizou da história, assim como da forma lógica e, portanto, científica de apresentar com aparente neutralidade os eventos ocorridos durante sua administração (a despeito das dificuldades precedentes e coetâneas no relacionamento com o poder público), de modo a transmitir a seus superiores os princípios que, em sua visão de especialista, deveriam reger as relações entre as autoridades políticas e as instituições científicas. Percebe-se, desse modo, não apenas as tensões, mas também as estratégias de negociação política em estilo científico levadas a efeito nesse caso.

A análise das estratégias de disseminação das práticas e conhecimentos científicos apresentada no artigo assinado por Luiza Massarani e Ildeu de Castro Moreira oferece uma visão bastante abrangente dos veículos de divulgação utilizados. Tais estratégias são detalhadas nesse e em outros artigos, com destaque para a criação de espaços e meios de divulgação científica como as Conferências Populares da Glória, realizadas em finais do século XIX, a publicação de livros e revistas de divulgação científica, tal como a Revista Brasileira, analisada por Moema de Rezende Vergara; a promoção de congressos nacionais e internacionais, entre eles o $1^{\circ}$ Congresso Brasileiro de Geografia, explorado por Sérgio Nunes; os congressos profissionais historiados por Moysés Kuhlmann; e as exposições científicas abordadas no artigo de Marta Almeida.

Enfim, a leitura do livro nos permite perceber a questão nacional e os fazeres científicos como processos imbricados no esforço de efetivação de um projeto civilizatório para o Brasil. A despeito dos matizes característicos dos diferentes projetos em curso - e a presença desses matizes é uma das qualidades do livro -, a associação entre os fazeres científicos e a tarefa política de modernizar o país em moldes republicanos se apresenta como ponto comum, tal como assinalam Ângela de Castro Gomes e Margarida Neves.

Contudo, como afirmamos, essa mesma leitura não nos autoriza a considerar que tal convergência fosse capaz de produzir consenso em torno do modelo de república a ser adotado, ou a respeito da concepção de ciência e de sua função social, tampouco em relação ao projeto de nação almejado. Quero com isso registrar que os autores não abrem mão da polifonia existente, seja no âmbito das questões analisadas em cada artigo, seja no conjunto de artigos que compõem o livro. 
Por tudo o que foi dito, recomendo a leitura do livro ou de partes dele, na sequência ditada pelo interesse de cada um. Devo, contudo, alertar o leitor de que dificilmente se poderá concluir a leitura de um artigo ou de um conjunto deles sem ceder ao exercício de autorreflexão a respeito de nossa própria identidade como brasileiros ou a respeito de nossa crença - apesar de tudo - na importância da ciência como instrumento organizador da vida contemporânea.

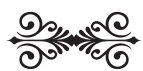

